\title{
PENGARUH PEMBERDAYAAN DAN MOTIVASI TERHADAP ORGANIZATIONAL CITIZENSHIP BEHAVIOR GURU SD NEGERI DI KECAMATAN BEKASI SELATAN
}

\author{
Erna Risnawati ${ }^{1}$
}

\begin{abstract}
The purpose of this research is to determine the effect of empowerment and motivation on organizational citizenship behavior in this teacher primary school south bekasi. The research methodology was survey which were selected by simple random sampling technique. Analysis and interpretation of the data indicate that (1) empowerment has a positive direct effect in organizational citizenship behavior, (2) motivation has a positive direct effect in organizational citizenship behavior, (3) empowerment has a positive direct effect in motivation.
\end{abstract}

Keywords: empowerment, motivation, organizational citizenship behavior.

\section{PENDAHULUAN}

Pendidikan sebagai salah satu upaya untuk membangun dan meningkatkan mutu sumber daya manusia menuju era globalisasi yang penuh dengan tantangan harus diarahkan menuju pendidikan yang visioner yaitu memiliki misi yang jelas sehingga menghasilkan keluaran yang bermutu. Oleh karena itu pendidikan tidak dapat diabaikan begitu saja, terutama dalam memasuki era persaingan yang semakin ketat tajam dan berat pada abad millennium ini.

Guru mempunyai peran strategis dalam menentukan mutu pendidikan. Hal itu terkait dengan peran penting guru sebagai pentransfer ilmu pengetahuan kepada peserta didik dan merupakan pihak yang paling aktif berinteraksi dengan peserta didik. Kondisi ini membuat posisi guru sangat penting dalam proses pendidikan dan pembelajaran. Dengan kondisi seperti itu, maka guru mempunyai andil besar dalam mewujudkan tujuan sekolah sebagai institusi pendidikan dan pusat pembelajaran, dan karena itu guru dituntut untuk memiliki ekstra peran atau organizational citizenship behavior $(O C B)$ yang dibutuhkan oleh dunia pendidikan, yaitu kesediaan secara terus menerus memerankan tugas atau pekerjaan melampaui standar yang seharusnya, bahkan melakukan hal-hal di luar peran utamanya sebagai pendidik.

Perilaku seperti ini sangat diperlukan oleh sekolah untuk mewujudkan tujuan pendidikan. Kondisi tersebut mengisyaratkan bahwa $O C B$ sangat penting bagi organisasi sekolah. Namun, dalam kenyataannya, masih banyak guru sebagai pelaku utama dalam proses pembelajaran yang belum memiliki. Diperkuat dengan hasil wawancara Kepala Dinas Pendidikan Kota Bekasi Bapak Rudi Sabarudin: "Pendidikan merupakan ujung tombak dari maju atau mundurnya suatu kota. Bekasi sebagai kota penyangga Ibu Kota Negara Indonesia. Kita harus mempersiapkan masyarakat yang bermutu dan berkualitas dengan cara memberikan pendidikan yang terbaik kepada anak didik kita." Guru sebagai motor penggerak di dalam dunia pendidikan dituntut lebih bekerja ekstra untuk mewujudkannya. Masih ada beberapa dari sebagaian guru yang sulit untuk dilakukan pemberdayaan untuk mewujudkan citacita "PENDIDIKAN CERDAS, BERKUALITAS, TAHUN 2013". Visi ini memiliki keterkaitan yang erat dengan visi Kota Bekasi yaitu: "Bekasi Cerdas, Sehat, dan Ihsan".

\footnotetext{
${ }^{1}$ Guru SD Negeri Di Kecamatan Bekasi Selatan.
} 
Saya terus berupaya untuk melakukan pemberdayaan dan memberikan motivasi kepada guru-guru untuk terus berusaha mewujudkan Visi dan Misi Kota Bekasi.

Idealnya jika manajemen berbasis sekolah ini dapat diterapkan secara murni, maka kepala sekolah dapat menerapkan pola kepemimpinan yang sesuai dengan karakteristik sekolah dan kepala sekolah mampu membagi pekerjaan kepada para guru sehingga terjadi sinkronisasi pekerjaan sehingga motivasi guru meningkat. Diperkuat dengan hasil wawancara yang dilakukan dengan kepala UPTD Bekasi Selatan Turyaman yang mengatakan:

Pada kenyataannya bahwa motivasi guru di lingkungan UPTD Pembinaan SD Kecamatan Bekasi Selatan Kota Bekasi masih rendah. Hal ini dapat dilihat dari rendahnya minat guru untuk mengikuti perlombaan-perlombaan, berkompetisi dalam kegiatan belajar mengajar, rendahnya minat untuk membuat penelitian tindakan kelas (PTK), enggan untuk mengikuti seminar-seminar pendidikan, enggan untuk mengikuti pemilihan guru teladan, menjalankan tugas seperti apa adanya, dan enggan untuk melanjutkan studi karena merasa tugas-tugas yang diberikan sulit.

Disisi lain perilaku guru dapat membentuk sikap memberikan pertolongan pada orang lain, menjadi volunter untuk tugas-tugas ekstra, patuh secara sepenuh hati pada peraturan yang berlaku. Hasil bentuk pemberdayan kerja seorang guru dan kepuasan terhadap kinerja yang dimiliki akan berdampak pada $O C B$. Hal tersebut dikarenakan pemberdayaan akan muncul ketika terdapat kepuasan kerja secara pribadi yang dirasakan oleh guru, ketika seseorang guru menyukai pekerjaanya. Kepuasan kerja akan didapat jika ada kecocokan antara harapan dan kenyataan yang diperoleh dari sekolah tempat bekerja. Kepuasan kerja guru akan didapat ketika dia berhasil dalam mengeksplorasi kemampuan yang dimiliki yang ditunjang dengan OCB. Maka hal ini yang menarik untuk dikaji lebih lanjut

Bertitik tolak dari keadaan di atas, maka peneliti memandang perlu adanya penelitian yang mengungkapkan pengaruh variabel pemberdayaan dan kepuasan terhadap $O C B$. Oleh karena itu, peneliti akan melakukan penelitian dengan judul "Pengaruh pemberdayaan dan motivasi terhadap organizational citizenship behavior guru SD Negeri di Kecamatan Bekasi Selatan.

\section{Organizational Citizenship Behavior (OCB)}

Pendapat Stephen P. Robbins, Timothy A. Judge (2015:58), "argued that OCB is a behavioral choice that does not become part of an employee's formal job duties, but support the functioning of the organization effectively". Stephen P. Robbins mengemukakan bahwa OCB merupakan perilaku pilihan yang tidak menjadi bagian dari kewajiban kerja formal seorang karyawan, namun mendukung berfungsinya organisasi tersebut secara efektif. Atau dengan kata lain, $O C B$ adalah perilaku karyawan yang melebihi peran yang diwajibkan, yang tidak secara langsung atau eksplisit diakui oleh sistem reward formal. Selanjutnya pendapat Organ (2002:205), "organizational citizenship behavior is the behavior of corporate employees who intended to enhance the effectiveness of corporate performance without sacrificing the productivity purposes of individual employees". OCB merupakan perilaku karyawan perusahaan yang ditujukan untuk meningkatkan efektifitas kinerja perusahaan tanpa mengabaikan tujuan produktifitas individual karyawan.

Pendapat Jason A. Colquitt, Jeffrey A, Lepine, Michael J Wesson(2015:39) Citizenship Behavior adalah, "citizenship behavior is defined as voluntary employee activities that may or may not be rewarded but that contibute to the organization by improving the overall quality of the setting in which work takes place". Citizenship behavior didefinisikan sebagai 
kegiatan sukarela karyawan yang mungkin atau mungkin tidak dihargai, tetapi berkontribusi untuk meningkatkan kualitas organisasi secara keseluruhan dengan pengaturan di mana pekerjaan berlangsung.

Senada yang diungkapkan oleh John W. Newstrom (2011:232) organizational citizenship behavior adalah, "organizational citizenship behavior, which are discretionary and helpful actions above and beyond the call of duty that promote the organization's success". OCB adalah kebebasan menentukan dan tindakan sangat menolong di atas dan di luar panggilan tugas yang mempromosikan sukses organisasi

Berdasarkan beberapa deskripsi konsep yang dipaparkan di atas, maka dapat disintesiskan $O C B$ adalah tindakan anggota organisasi yang muncul secara sukarela membantu individu lain berkaitan dengan tugas dan pekerjaan organisasi dengan indikator 1). Altruism (perilaku membantu), 2). Conscientiousness (mengacu kepada tepat waktu), 3). Sportmanship (menghindari keluhan), 4). Courtesy (Kesopanan), dan 5). Civic virtue (partisipasi tanggung jawab dalam kehidupan politik organisasi).

\section{Pemberdayaan}

Memberdayakan dapat dinyatakan sebagai suatu hal yang mendorong untuk menjadi lebih terlibat dalam mengambil keputusan dan beraktivitas yang berhubungan dengan pekerjaan. Setiap individu dalam pemberdayaan memungkinkan membuat keputusan lebih besar dan lebih banyak tanpa harus mengacu pada sesorang yang lebih senior. Menurut pendapat Neilsel. E, yang dikutip oleh Anthony Walker (2011:125), "empowerment is giving subordinates the resources, both psychological and technical, to discover the varieties of power themselves have and or accumulate and therefore which they can use on another's behalf". Pemberdayaan adalah memberikan bawahan sumber daya, baik psikologis dan teknis, untuk menemukan varietas kekuasaan sendiri memiliki dan atau menumpuk dan karena itu yang dapat mereka gunakan atas nama orang lain.

Selanjutnya Edwin P. Hollander and Lynn R. Offermann, yang di kutip oleh Ricard L. Daft(2010:271), "empowerment is power sharing, the delegation of power or authority to subordinates in an organization". Pemberdayaan adalah pembagian kekuasaan, pendelegasian kekuasaan atau wewenang kepada bawahan dalam suatu organisasi. Menurut Ricky W. Griffin, Gregory Moorhead (2014:132), "empowerment is the process of enabling workers to set their own work goals, make decisions and solve problems within their spheres of responsibility and authority." Pemberdayaan adalah proses yang memungkinkan pekerja untuk menetapkan tujuan pekerjaan mereka sendiri, membuat keputusan dan memecahkan masalah dalam bidang tanggung jawab dan wewenang.

Pendapat lain oleh Robert C. Ford and Myron D. Fottler yang di kutip oleh John W. Neswtrom (2014:195), "empowerment is any process that provides greater autonomy to employees throught the sharing of relevant information and the provision of control over factors affecting job performance". Pemberdayaan adalah setiap proses yang memberikan otonomi yang lebih besar kepada karyawan pikir berbagi informasi yang relevan dan penyediaan kontrol atas faktor yang mempengaruhi prestasi kerja.

Berdasarkan beberapa konsep yang telah dikemukakan dapat disintesiskan bahwa pemberdayaan adalah proses yang dilakukan pimpinan dalam memanfaatkan dan mengembangkan potensi pegawai untuk meningkatkan kinerja pegawai untuk mencapai tujuan organisasi dengan indikator pemberian otonomi, pemanfaatan sumber daya, dan meningkatkan partisipasi. 


\section{Motivasi}

Menurut Jason A. Colquitt, Jeffery A. Lepine, Michael J. Wesson (2015:168). Motivasi, "motivation is defined as a set of energetic forces that originates both within and outside an employee, initiates work related effort and determine its direction, intensity and persistence". Motivasi didefinisikan sebagai seperangkat kekuatan energik yang berasal baik di dalam maupun di luar karyawan, memulai usaha yang berhubungan dengan pekerjaan dan menentukan arah, intensitas dan ketekunan.

Selanjutnya Fred Luthans (2011:157) mengatakan, "motivation is a process that starts with physiological or psychological deficiency or need that activates a behavior or a drive that is aimed at a goal or incentive". Motivasi adalah proses yang dimulai dengan defisiensi fisiologis atau psikologis atau kebutuhan yang mengaktifkan perilaku yang ditujukan untuk tujuan atau insentif.

Menurut John Ivancevich, Robert konopaske (2013:54) mengatakan, "motivation is the set off atitiudes predispose a person to act a specific goal-directed way". Motivasi adalah atitiudes berangkat mempengaruhi seseorang untuk bertindak dengan cara yang diarahkan pada tujuan tertentu. Selanjutnya Kreitner, Robert, Angelo Kinicki (2008:147) menyatakan "motivation represents "those psychological processes that cause the arousal,direction and persistence of voluntary actions that are goal directed". Motivasi mewakili proses psikologi yang berakibat pada peningkatan, tujuan/ arah dan kegigihan dalam melakukan sesuatu secara suka rela yang mengacu pada tujuan yang ingin dicapai.

Hal senada di ungkapkan oleh Steven L. McShane and mary Ann Von Glinow (2010:132), " motivation refers to the forces within a person that affect the direction, intensity and persistence of voluntary behavior". Sejumlah teori dan konsep menjelaskan alasan mengapa karyawan lebih termotivasi daripada yang lain. Menurut Donald C. Mosley Jr., Donald C. Mosley Sr., Paul H. Pietri (2005195), "motivation is willingness to work to achieve the organization's objectives". Motivasi adalah kemauan untuk bekerja untuk mencapai tujuan organisasi

Dari konsep di atas dapat disintesiskan motivasi adalah dorongan yang menyebabkan anggota organisasi bekerja secara gigih dan suka rela dalam mencapai tujuan organisasi dengan indikator 1). memiliki tujuan yang realistis dalam bekerja, 2). memiliki perencanaan untuk mewujudkan tujuan dalam bekerja, 3). kesediaan dalam menerima umpan balik, 4). kesediaan bertanggung jawab, 5). kesediaan menyelesaikan tugas dengan baik, 6). bekerja keras dalam menyelesaikan pekerjaan 


\section{METODE PENELITIAN}

Penelitian ini menggunakan metode survey dengan teknik analisis jalur (path analysis). Data penelitian ini dikumpulkan dengan cara memilih sampel dalam populasi. Populasi terjangkau dalam penelitian ini adalah seluruh guru SD Negeri di Kecamatan Bekasi Selatan yang berstatus PNS yang berjumlah 374 guru. Dan perhitungan dengan menggunakan slovin, maka di peroleh jumlah sampel sebanyak 193 guru yang dijadikan sampel frame dalam penelitian ini. Teknik pengumpulan data yang digunakan untuk penelitian ini adalah kuesioner. Selanjutnya dilakukan uji coba intrumen untuk menentukan butir-butir instrumen yang valid dan reliabel. Teknik analisis data dilakukan dengan statistika deskriptif dan statistika inferensial dengan terlebih dahulu melakukan uji prasyarat analisis yaitu normalitas populasi dan analisis regresi.

\section{HASIL PENELITIAN DAN PEMBAHASAN}

\section{Pengaruh Pemberdayaan terhadap Organizational Citizenship Behavior.}

Berdasarkan hasil perhitungan koefisien korelasi 0.239 dan nilai koefisien jalur sebesar 0.198. hal ini bermakna bahwa pemberdayaan berpengaruh secara langsung terhadap $O C B$.

Hasil penelitian ini sesuai dengan pendapat Stephen P. Robbins, Timothy A. Judge (2015:59) di dalam bukunya Organizational behavior 16 edition, "citizenship behavior the discretionary behavior that is no part of an employee's formal job requirements and that contributes to the psychological and social environment of the workplace, is called citizenship behavior. successful organizations need employees who will do more than their usual job duties who will provide performance beyond expectations. in today's dynamic workplace, where task are increasingly performed by teams and flexibility is critical, employees who engage in good citizenship behavior help others on their team, volunteer for extra work, avoid unnecessary conflict, respect the spirit as well as the letter of rules and regulations and gracefully tolerate occasional work related impositions and nuisances". Perilaku OCB yang bukan bagian dari persyaratan kerja formal karyawan dan yang memberikan kontribusi untuk lingkungan psikologis dan sosial dari tempat kerja, disebut perilaku kewarganegaraan. Organisasi yang sukses membutuhkan karyawan yang akan melakukan lebih dari tugas pekerjaan mereka biasa yang akan memberikan kinerja yang melampaui harapan di tempat kerja yang dinamis saat ini, di mana tugas semakin dilakukan oleh tim dan fleksibilitas yang penting, karyawan yang terlibat dalam perilaku kewarganegaraan yang baik membantu orang lain dalam tim mereka, rela untuk bekerja ekstra, menghindari konflik yang tidak perlu, menghormati semangat serta peraturan dan mentolerir beberapa pekerjaan yang sewaktu-waktu mendesak serta mengganggu ( di luar jam kerja). Organ (2002:205) menjelaskan, "organizational citizenship behavior is the behavior of corporate employees who intended to enhance the effectiveness of corporate performance without sacrificing the productivity purposes of individual employees". OCB merupakan perilaku karyawan perusahaan yang ditujukan untuk meningkatkan efektifitas kinerja perusahaan tanpa mengabaikan tujuan produktifitas individual karyawan. Pendapat Jason A. Colquitt, Jeffrey A, Lepine, Michael J Wesson(2015:39) Citizenship Behavior adalah, "citizenship behavior is defined as voluntary employee activities that may or may not be rewarded but that contibute to the organization by improving the overall quality of the setting in which work takes place". Citizenship behavior didefinisikan sebagai kegiatan sukarela karyawan yang mungkin atau mungkin tidak dihargai, tetapi berkontribusi untuk meningkatkan kualitas organisasi secara keseluruhan dengan pengaturan di mana pekerjaan 
berlangsung. Senada yang diungkapkan oleh John W. Newstrom (2011:232) organizational citizenship behavior adalah, "organizational citizenship behavior, which are discretionary and helpful actions above and beyond the call of duty that promote the organization's success". OCB adalah kebebasan menentukan dan tindakan sangat menolong di atas dan di luar panggilan tugas yang mempromosikan sukses organisasi. Sedangkan Ricky W. Griffin, Gregory Moorhead (2014:132) menjelaskan, "empowerment is the process of enabling workers to set their own work goals, make decisions and solve problems within their spheres of responsibility and authority." Pemberdayaan adalah proses yang memungkinkan pekerja untuk menetapkan tujuan pekerjaan mereka sendiri, membuat keputusan dan memecahkan masalah dalam bidang tanggung jawab dan wewenang. Dengan demikian, ketepatan dalam pemberdayaan akan mengakibatkan peningkatan OCB seseorang.

\section{Pengaruh motivasi terhadap organizational citizenship behavior}

Dari hasil pengujian hipotesis kedua dapat disimpukan bahwa terdapat pengaruh langsung positif motivasi terhadap $O C B$ dengan nilai koefisien korelasi sebesar 0,251 dan nilai koefisien jalur sebesar 0,213. Ini memberikan makna motivasi berpengaruh langsung terhadap OCB.

Hasil penelitian ini senada dengan pendapat beberapa ahli di antaranya adalah Stephen P. Robbins, Timothy A. Judge (2015:224), “ in organizations that focus more on behaviors, following your motivation to be a good citizen can help to accomplish your career goals". Dalam organisasi yang lebih berfokus pada perilaku, berikut motivasi Anda untuk menjadi warga negara yang baik dapat membantu untuk mencapai tujuan karir Anda Di duga hasil Risert Stephen P. Robbins, Timothy A. Judge mengatakan bahwa motivasi memiliki pengaruh terhadap $O C B$.

Selanjutnya hasil riset yang dilakukan oleh Lei Wang, Jon P. Howell, Kim T. Hinrichs and Leonel Prieto dengan judul, "Organizational Citizenship Behavior: The Role of Value/Identity-Based Motivation"." this study is one of the very limited empirical research efforts on the value/identity-based motivation (VIM) theory proposed by Shamir. In this research, the authors tested the relationships between VIM and the five dimensions of organizational citizenship behavior (OCB) as well as the moderating effects of individualistic/collectivistic orientation on the relationships between VIM and OCB dimensions. Data were collected from employees and their immediate supervisors in organizations located in the Midwestern and Southwestern United States. The results support the hypothesized relationships between VIM and sportsmanship, civic virtue, courtesy, and altruism but failed to support the expected relationship between VIM and conscientiousness and the moderating effects. The findings of this study provide evidence for the validity of VIM as a theory of motivation for organizational behaviors, particularly in "weak situations," and contribute to the body of knowledge regarding the antecedents of $O C B^{\prime \prime}$ Penelitian ini merupakan salah satu upaya penelitian sangat terbatas empiris pada nilai/motivasi berbasis identitas (VIM) teori yang diusulkan oleh Shamir. Dalam penelitian ini, penulis menguji hubungan antara VIM dan lima dimensi perilaku organisasi kewarganegaraan (OCB) serta efek moderasi dari individualistik/orientasi kolektif pada hubungan antara VIM dan OCB dimensi. Data dikumpulkan dari karyawan dan supervisor langsung mereka dalam organisasi yang terletak di Midwestern dan Barat Amerika Serikat. Hasil mendukung hipotesis hubungan antara VIM dan sportivitas, civic virtue, sopan santun, dan altruisme tetapi gagal untuk mendukung hubungan antara diharapkan VIM dan kesadaran dan efek moderasi. Temuan penelitian ini memberikan bukti atas kebenaran VIM sebagai teori 
motivasi bagi perilaku organisasi, terutama dalam "situasi yang lemah," dan memberikan kontribusi pada tubuh pengetahuan mengenai anteseden $O C B$. Fred Luthans (2011:157) mengatakan, "motivation is a process that starts with physiological or psychological deficiency or need that activates a behavior or a drive that is aimed at a goal or incentive". Motivasi adalah proses yang dimulai dengan defisiensi fisiologis atau psikologis atau kebutuhan yang mengaktifkan perilaku yang ditujukan untuk tujuan atau insentif. Menurut John Ivancevich, Robert konopaske (2013:54), " motivation is the set off atitiudes predispose a person to act a specific goal-directed way". Motivasi adalah atitiudes berangkat mempengaruhi seseorang untuk bertindak dengan cara yang diarahkan pada tujuan tertentu.Dengan demikian peningkatan motivasi akan berdampak pada peningkatan $O C B$.

\section{Pengaruh pemberdayaan terhadap motivasi}

Dari hasil pengujian hipotesis ketiga dapat disimpulkan bahwa terdapat pengaruh langsung positif pemberdayaan terhadap motivasi dengan nilai koefisien korelasi sebesar 0,191 dan nilai koefisien jalur sebesar 0,191. Ini memberikan makna pemberdayaan berpengaruh langsung terhadap motivasi.

Menurut Stephen P. Robbins, Timothy A. judge (2015:258), "employee involvement is a participative process that uses employees input to increase their commitment to the organization's success. The logic is that if we engage workers in decisions that affect them and increases their autonomy and control over their work lives, they will become more motivated, more commitment to the organization, more productive and more satisfied with their jobs. These benefits don't stop with individuals when teams are given more control over their work, morale and performance increase". Keterlibatan karyawan adalah proses partisipatif yang menggunakan masukan karyawan untuk meningkatkan komitmen mereka terhadap keberhasilan organisasi. Logikanya adalah bahwa jika kita terlibat pekerja dalam pengambilan keputusan yang mempengaruhi mereka dan meningkatkan otonomi dan kontrol mereka atas kehidupan pekerjaan mereka, mereka akan menjadi lebih termotivasi, lebih komitmen terhadap organisasi, lebih produktif dan lebih puas dengan pekerjaan mereka. Manfaat ini tidak berhenti dengan individu ketika tim diberikan lebih banyak kontrol atas pekerjaan, semangat dan kinerja meningkat mereka.

Pendapat lain oleh Jay A.Conger and Rabindra N.Kanungo, yang di kutip oleh Ricard L. Daft (2010:203), “increasing employee power heightens motivation for task accomplishment because people improve their own effectiveness, choosing how to do a task and using their creativity". Meningkatkan kekuatan karyawan mempertinggi motivasi untuk penyelesaian tugas karena orang meningkatkan efektivitas mereka sendiri, memilih bagaimana melakukan tugas dan menggunakan kreativitas mereka. Diduga bahwa pemberdayaan memiliki pengaruh terhadap motivasi.

Hal senada di ungkapkan oleh Steven L. McShane and / mary Ann Von Glinow (2010:132), " motivation refers to the forces within a person that affect the direction, intensity and persistence of voluntary behavior". Sejumlah teori dan konsep menjelaskan alasan mengapa karyawan lebih termotivasi dari pada yang lain. Penjelasan dari konsep di atas menyatakan bahwa motivasi adalah suatu konsep yang dapat digunakan ketika menggerakkan individu untuk memulai dan berperilaku secara langsung sesuai yang dikehendaki oleh pemimpin. Artinya seorang pemimpin yang ingin menggerakkan orang lain untuk mengerjakan tugas-tugasnya dengan baik haruslah mampu memotivasi mereka sehingga mereka akan memusatkan seluruh tenaga dan perhatianya untuk mencapai hasil yang ditetapkan. Ricky W. Griffin, Gregory 
Moorhead (2014:132) menjelaskan, "empowerment is the process of enabling workers to set their own work goals, make decisions and solve problems within their spheres of responsibility and authority." Pemberdayaan adalah proses yang memungkinkan pekerja untuk menetapkan tujuan pekerjaan mereka sendiri, membuat keputusan dan memecahkan masalah dalam bidang tanggung jawab dan wewenang. Sedangkan Robert C. Ford and Myron D. Fottler yang di kutip oleh John W. Neswtrom (2014:195) mendeskripsikan, "empowerment is any process that provides greater autonomy to employees throught the sharing of relevant information and the provision of control over factors affecting job performance". Pemberdayaan adalah setiap proses yang memberikan otonomi yang lebih besar kepada karyawan pikir berbagi informasi yang relevan dan penyediaan kontrol atas faktor yang mempengaruhi prestasi kerja. Dengan demikian, ketepatan dalam pemberdayaan, maka akan mengakibatkan peningkatan motivasi.

\section{PENUTUP}

Kesimpulan: Pertama, pemberdayaan berpengaruh langsung positif terhadap $O C B$. Artinya ketepatan dalam memberdayakan guru akan mengakibatkan peningkatan $O C B$ guru SD Negeri di Kecamatan Bekasi Selatan. Kedua, motivasi berpengaruh langsung positif terhadap $O C B$. Artinya ketepatan motivasi dalam bekerja akan mengakibatkan peningkatan $O C B$ guru SD Negeri di Kecamatan Bekasi Selatan. Ketiga, pemberdayaan berpengaruh langsung positif terhadap motivasi. Artinya ketepatan dalam pemberdayaan akan mengakibatkan peningkatan motivasi guru SD Negeri di Kecamatan Bekasi Selatan.

Saran: Berdasarkan kesimpulan penelitian disarankan berbagai upaya yang dilakukan dalam rangka meningkatkan OCB guru SD Negeri di Kecamatan Bekasi Selatan. (1) Bagi Kepala Dinas Pendidikan Kota Bekasi, untuk membantu meningkatkan OCB guru dengan meningkatkan pemberdayaan dan motivasi kepada guru agar dapat menumbuhkan sikap $O C B$ di setiap guru. (2) Bagi kepala sekolah dapat meningkatkan pemberdayaan kepada guru dengan memberikannya otonomi yang luas dalam bekerja dan berdampak kepada peningkatan motivasi kerja guru yang juga akan berdampak kepada tumbuhnya sikap $O C B$ disetiap guru. (3) Bagi peneliti lain, dapat dijadikan bahan rujukan dalam rangka peneliti lebih lanjut terkait dengan pemberdayaan dan motivasi terhadap $O C B$. 


\section{DAFTAR RUJUKAN}

Colquitt, Jason A., Jeffrey A, Lepine, Michael J Wesson, organization behavior improving performance and commitment in the workplace 4 edition. New York: Mc Graw Hill, 2015.

Daft., Richard L. Understanding the theory design of organizations tenth Edition. China: South Western Camgage Learning, 2010.

De Janasz, Suzanne C., Karen O. Dowd, Beth Z. Schneider, Interpersonal Skill in Organization 4 edition. New York:McGraw Hill, 2012.

George, Jenniver M, Gareth R Jones, Essentials of Contemporary Management fifth edition (New York: Mc Graw Hill, 2013.

Gibson, James L., John M.Ivancevich, James H. Donnelly jr, Robert Konopaske, Organizations Behavior, Structure, Processes. New York : McGraw-Hill/Irwin Companies Inc, 2012.

Griffin, Ricky W., Gregory Moorhead, Organizational Behavior Managinig People and Organizations 11 Ediiton. Canada, South Western: Cengage Learning, 2014.

Ivancevich, John M., Robert Konopaske, Human Resource Management. New York: McGraw Hill, 2013.

Ivancevich.John M., Robert Konopaske, and Michael T. Matteson, Organizational Behavior and Management 10 Edition. New York: McGraw-Hill Companies, Inc., 2014.

Kreitner, Robert, Angelo Kinicki, Organizational Behavior, Key Concepts, Skills and Best Practices. New York: Mc Graw-Hill Companies, Inc, 2008.

--------,Organization Behavior 9 Edition. New York: McGraw Hill, 2011.

Larsen, Randy J., David M. Buss, Personality Psychology domains of knowledge about human nature 5 edition. New York: McGraw Hill, 2014.

Luthans, Fred, Organizational Behaviour an Evidence based approach, 12 Edition. New York, Mc Graw Hill, 2011.

Mosley, Donald C. Jr., Donald C. Mosley Sr., Paul H. Pietri, Supervisory Management The art of inspiring, empowering and developing people 8 Edition. USA: Cengage learing, 2011.

Mullins, Laurie J., Management and Organizational Behaviour 9 edition. England: FT Prentice Hall, 2010.

Newstrom, John W., Organization Behavior human behavior at work 14 Edition. New York: McGraw-Hill/Irwin Companies Inc, 2015. 
Robbins, Stephen P., Timothy A. Judge, Organizational Behavior 16 Edition. England: Pearson, 2015.

Walker, Antohny, Organizational Behavior in Construction. England: Johny Wiley, 2011. 